\title{
Abdominal Scar Endometrioma Mimicking Incisional Hernia: A Diagnostic Pitfall
}

\author{
Abdulla Alabassi Medhat M. Farghaly \\ Department of Surgery, Al-Adan Hospital, Kuwait
}

Key Words

Endometriosis · Abdominal scar · Incisional hernia

\begin{abstract}
Objective: Abdominal scar endometriosis is a recognized condition that has been described following a wide variety of gynaecological procedures. We report a case of endometrioma, presenting as a painful subumbilical swelling, mimicking an incarcerated incisional hernia. Clinical Presentation: A 35-year-old woman presented with a painful subumbilical swelling that had been present for 6 months, but had increased in size and become more painful the day prior to admission. Her past medical history included four caesarean sections. Physical examination revealed a firm, tender and irreducible subumbilical nodule with no cough impulses, mimicking a small incarcerated incisional hernia. Intervention: Exploratory laparotomy through the same lower midline incision revealed a subcutaneous swelling resembling an organized chocolate cyst of endometriosis. Apart from intra-abdominal adhesions, no connection to intra-abdominal structures was identified. Histopathology of the specimen was consistent with abdominal scar endometriosis. Conclusion: Endometrioma was diagnosed in this 35-year-old woman following histological
\end{abstract}

examination of a specimen removed during laparotomy. It is recommended that endometrioma should be considered in the differential diagnosis of subcutaneous, scarrelated hernias and various abdominal wall masses following gynaecological operations.

Copyright $@ 2001$ S. Karger AG, Basel

\section{Introduction}

Endometriosis is an aberrant or heterotopic growth of glands and stroma identical to the lining of the uterus [1]. It is a well-recognized gynaecological condition affecting $8-15 \%$ of menopausal women $[1,2]$ and presents infrequently to the general surgeon [3].

Abdominal scar endometriosis is rare. It appears in 0.1$1 \%$ of women who have undergone caesarean section. Up to $25 \%$ of these women have concomitant pelvic endometriosis [3, 4]. It usually presents as a scar-related nodule or subcutaneous swelling that increases in size and becomes tender during menstruation $[1,3,5]$. Skin colour changes related to subcutaneous bleeding may be present [1].

We report a case of scar-related endometrioma presenting as a painful subumbilical swelling that became more severe on coughing and straining, mimicking an incarcerated incisional hernia.

\begin{tabular}{ll}
\hline KARGER & ( ) 2001 S. Karger AG, Basel \\
Fax +416130612 34 & 1011-7571/01/0104-0207\$17.50/0 \\
$\begin{array}{l}\text { E-Mail karger@karger.ch } \\
\text { www.karger.com }\end{array}$ & $\begin{array}{l}\text { Accessible online at: } \\
\text { www.karger.com/journals/mpp }\end{array}$
\end{tabular}

Dr. Medhat M. Farghaly, FRCSI, FACS

Consultant General and Vascular Surgeon

PO Box 51601, 53457 Riqqa (Kuwait)

Tel./Fax +9653919333 

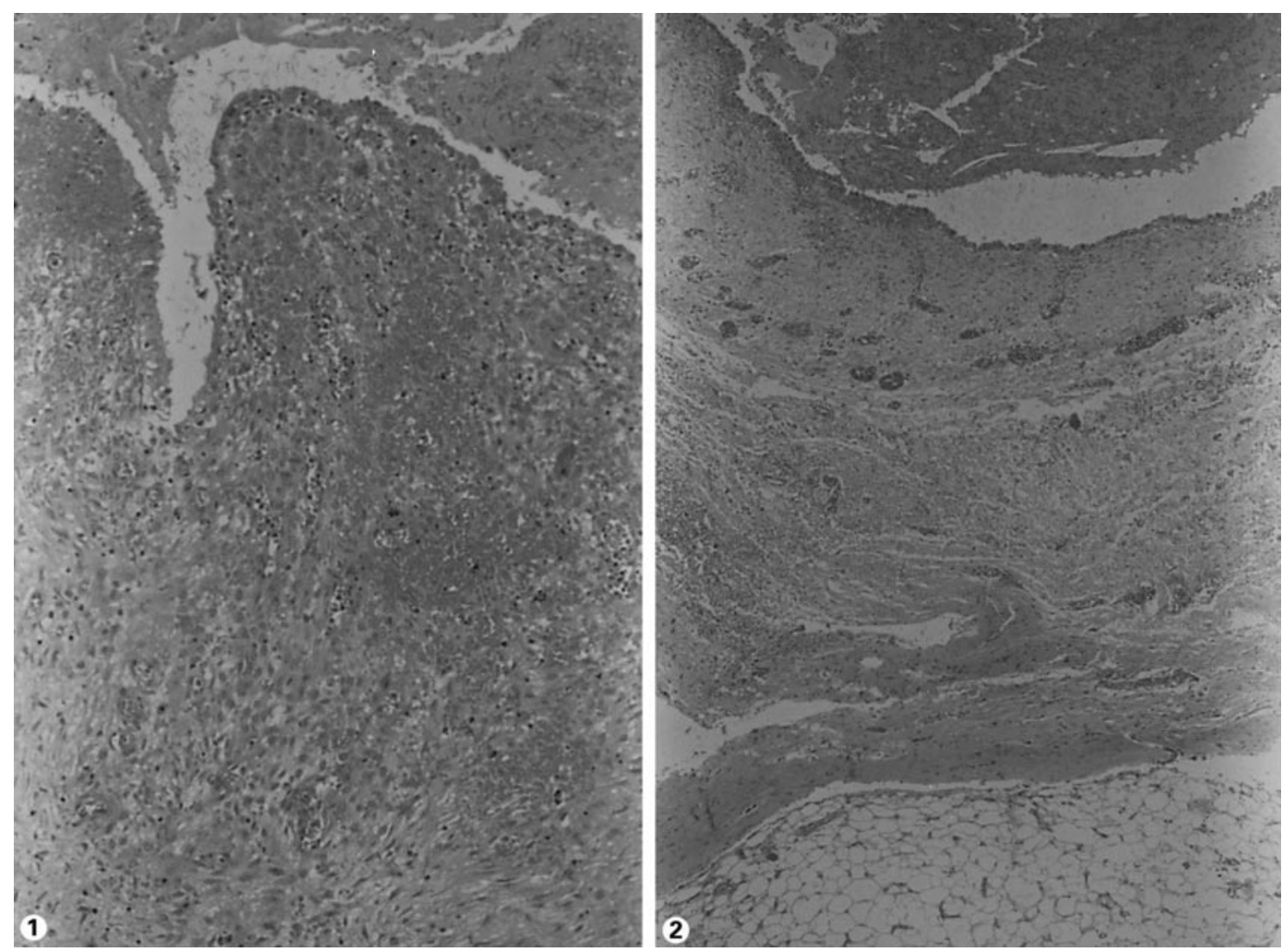

Fig. 1. Endometriosis focus showing epithelial surface, inflammatory process with a haemorrhage and reactive fibrosis. HE. $\times 20$.

Fig. 2. Abdominal wall and subcutaneous tissue with focus of endometriosis, showing epithelial (glandular) portion and inflammation. HE. $\times 20$.

\section{Case Report}

A 35-year-old woman presented to the emergency department with a chief complaint of a painful subumbilical swelling that had been present for 6 months. It gradually increased in size and became more painful the day prior to admission. The pain increased with coughing and straining, and was not related to menstruation. The patient had no associated gastro-intestinal, menstrual, or constitutional symptoms. Her past medical history included four caesarean sections at 3,6,8 and 11 years previously. The first caesarean section was through a lower midline incision, and the other three were through Pfannenstiel's incisions. The physical examination revealed a firm, tender and irreducible subumbilical nodule, measuring $2 \times$ $3 \mathrm{~cm}$ with no visible or palpable cough impulses. No skin colour changes around the umbilicus were observed. The rest of the physical examination was unremarkable. Laboratory investigations revealed a normal haemoglobin level and a leucocyte count of $15,000 / \mathrm{ml}$. Plain X-ray of the abdomen was normal.

A provisional laparotomy of a small incarcerated incisional hernia was made. Exploratory laparatomy through the same lower midline incision of the first caesarean section was performed. A subcutaneous swelling resembling an organized chocolate cyst of endometriosis was found, and it leaked a brownish greenish material into the subcutaneous tissue. This was excised along with a 1-cm safety margin and sent for histological examination. A formal abdominal-pelvic exploration was performed. Apart from intra-abdominal adhesions, no intra-abdominal pathology was found, and no connection to intra-abdominal structures was identified. Anatomical repair of the incision was performed. Apart from a postoperative paralytic ileus, which improved by nasogastric suction and intravenous fluids, the patient had a smooth post-operative period and was discharged home 7 days after surgery. Histopathology of the specimen revealed fibro-fatty tissue including haemorrhagic areas and few endometriallike glands compatible with endometriosis (fig. 1,2).

\section{Discussion}

Abdominal wall scar endometriosis has been described after a wide variety of gynaecological procedures including caesarian section, hysterectomy, and surgery for pyosalpinx and tubo-ovarian abscesses [2, 3, 6]. It has also been described following amniocentesis [7]. 
The development of endometriosis in the abdominal wall scar occurs primarily through iatrogenic implantation of endometrial cells transplanted by surgical instruments. These cells proliferate and respond to the monthly hormonal influences, resulting in the typical waxing and waning of discomfort associated with menses $[1,2,8]$.

The interval between prior surgical treatment and the onset of symptoms is very variable, ranging from 1 to 2 years [9]. However, a majority of the patients manifested symptoms 1 year after the primary operative procedure [5].

The most frequent presentation is a subcutaneous nodule closely resembling the abdominal wall incision. Abdominal scar endometriosis should be suspected if the lesion increases in size and becomes tender during menstruation $[3,5,8]$. However, the pain is often continuous rather than cyclical if the lesion is long-standing. In such a case, the presentation to the general surgeon may be atypical, and pose a diagnostic difficulty [3, 9, 10]. Endometrioma in a scar can also present as a painful swelling that becomes worse during coughing and straining and resembles an incarcerated incisional hernia $[6,11]$.

The differential diagnosis includes incisional, umbilical or para-umbilical hernias, stitch granuloma, haematoma, sebaceous cyst, desmoid tumour, and metastatic nodule from an intra-abdominal malignancy (Sister Joseph's nodule) $[2,3,4,8]$.

A high index of suspicion is necessary for diagnosis. Patients with a history of transabdominal surgery and classical presentation of a painful scar mass that increases in size or tenderness during menstruation need no further evaluation of the lesion before excision $[9,12]$.

Endometriosis has no pathognomonic findings on computed tomography or sonography, as appearance de- pends on the phase of the menstrual cycle, the proportions of stromal and glandular elements, the amount of bleeding and the degree of surrounding inflammation and fibrotic response [2]. Magnetic resonance imaging may be useful in diagnosing endometrial tissue from surrounding structures. It also allows detection of recent haemorrhage and haemosiderosis from previous bleeding that may have occurred with endometrioma [2].

Fine needle aspiration biopsy should be considered pre-operatively in women who have an asymptomatic or constantly painful mass in a surgical scar [9]. Endometrial cells in the aspirate arranged in syncytial clusters suggest the diagnosis [13]. The histological diagnosis requires a combination of either endometrial-like glands, endometrial stroma or haemosiderin pigment [12].

Hormonal treatment usually results in incomplete regression of endometriomas. Therefore the recommended treatment is wide local excision to prevent local recurrence $[3,5,9,11]$.

Since pelvic endometriosis may be present in up to $25 \%$ of patients, referral to a gynaecologist is recommended in every case $[3,4]$.

\section{Conclusion}

A provisional diagnosis of a small incarcerated incisional hernia was made as endometrioma following histological examination of the specimen removed during laparatomy. It is recommended that endometrioma should be considered in the differential diagnosis of subcutaneous scar-related hernias and various abdominal wall masses following gynaecological operations.

\section{References}

1 Roberge RJ, Kantor WJ, Scorza L: Rectus abdominis endometrioma. Am J Emerg Med 1999; 17:675-677

2 Coley BD, Casola G: Incisional endometrioma involving the rectus abdominis muscle and subcutaneous tissues. CT appearance. AJR Am J Roentgenol 1993;160:549-550.

3 Singh KK, Lessells AM, Adam DJ, Jordan C, Miles WF, Macintyre IM, Greig JD: Presentation of endometriosis to general surgeons: A 10year experience. Br J Surg 1995;82:1349_ 1351.

4 Wolf Y, Haddad R, Werbin N, Skornick Y, Kaplan O: Endometriosis in abdominal scars: A diagnostic pitfall. Am Surg 1996;62:10421044.
5 Xiang Y, Lang J, Wang Y, Huang R, Lian L: Abdominal scar endometriosis: Report of 28 cases. Chin Med Sci J 1995;10:188-190.

6 Sataloff DM, La Vorgna KA, McFarland MM: Extrapelvic endometriosis presenting as a hernia: Clinical reports and review of the literature. Surgery 1989;105:109-112.

7 Kaunitz A, Di Sant'Agnese PA: Needle tract endometriosis: An unusual complication of amniocentesis. Obstet Gynecol 1979;54:753755.

8 Marder DM, McGahan JP, Brant WE, Leeba J: Imaging of periumbilical endometriosis. AJR Am J Roentgenol 1991;156:636-637.
9 Koger KE, Shatney CH, Hodge K, McClenathan JH: Surgical scar endometrioma. Surg Gynaecol Obstet 1993;177:243-246.

10 Rovito P, Gittleman M: Two cases of endometrioma in cesarean scars. Surgery 1986;100: 118-120.

11 Patterson GK, Winburn GB: Abdominal wall endometriomas: Report of eight cases. Am Surg 1999;95:36-39.

12 Chun JT, Nelson HS Jr, Maull KI: Endometriosis of the abdominal wall. South Med J 1990;83:1491-1492.

13 Griffin JB, Betsill WL Jr: Subcutaneous endometriosis diagnosed by fine needle aspiration cytology. Acta Cytol 1985;29:584-588. 